\title{
Review of Hyperuricaemia and Hypertension: A Target for Treatment
}

Claudine G Jennings, Isla S Mackenzie and Thomas M MacDonald

Dundee University, Medicines Monitoring Unit, Ninewells Hospital, Dundee DD1 9SY, USA

*Corresponding author: Claudine Jennings, Medicine Monitoring Unit, Ninewells Hospital, Dundee, DD1 9SY, USA, Tel: 01382383119 , Fax: 01382 740209; E-mail: claudine@memo.dundee.ac.uk

Received date: June 20, 2014; Accepted date: July 25, 2014; Published date: August 03, 2014

Copyright: (C) 2014 Jennings C, et al. This is an open-access article distributed under the terms of the Creative Commons Attribution License, which permits unrestricted use, distribution, and reproduction in any medium, provided the original author and source are credited.

\begin{abstract}
Hypertension is a significant cardiovascular risk factor with multifactorial aetiology. The link between hypertension and hyperuricaemia has been noted for over a century however determining whether this link is causal and whether there is a role for management of hyperuriaemia in the context of hypertension has been more problematic. Over the past two decades research in this area has dramatically increased with development of animal models of hyperuricaemia and use of large observational cohorts. There is an emerging body of evidence that hyperuricaemia should be considered an independent risk factor for the development of essential hypertension and that further research into the management of hyperuricaemia is required.
\end{abstract}

Keywords: Hypertension; Hyperuricaemia; Cardiovascular risk

\section{Introduction}

Hypertension is a leading risk factor for cardiovascular disease and worldwide prevalence of hypertension is increasing. In $200026 \%$ of the world's adult population (over 1 billion people) were considered to have hypertension and in 2009 the WHO reported that hypertension had a causative role in the deaths of over 7.5 million people $[1,2]$ Prevalence of hypertension in adults of 16 years or older in the UK was $31.5 \%$ in men and $29.0 \%$ in women in 2010 [3]. The majority of hypertension is considered to be essential hypertension which develops due to a complex interplay of genetic, lifestyle and environmental factors. Cardiovascular risk associated with increasing blood pressure is continuous with $7 \%$ increase in mortality from ischaemic heart disease and $10 \%$ increased risk of mortality from stroke for every $2 \mathrm{mmHg}$ rise in population blood pressure [4].

Therefore even small improvements in population blood pressure control are likely to have a significant impact on long term public health. Significant efforts are directed at addressing hypertension as a cardiovascular risk factor and one area that has fallen in and out of favour over the years is the role of hyperuricaemia in the development of hypertension and as a potentially modifiable cardiovascular risk factor. There is a growing body of evidence supporting the association between hyperuricaemia and the metabolic syndrome [5], chronic kidney disease [6] and atherosclerosis [7] as well as hypertension which will be the focus of this review. The question that now needs to be answered is whether there is a role for actively lowering serum urate levels to better manage these associated conditions. Small trials have been conducted looking at whether reduction of serum urate levels influences blood pressure control and there is now a growing consensus that a large randomised controlled trial is needed to finally answer this question [8].

PubMed, Web of Science and Medline databases were searched using the terms hyperuricaemia, uric acid, urate, hypertension, blood pressure, cardiovascular, xanthine oxidase inhibitor, uricosuric, allopurinol and febuxostat in English language publications from 1975 to July 2013. Abstracts were reviewed by category and references retrieved for papers meeting relevance criteria, reference lists of selected papers were scrutinised for relevant papers and data synthesised by themes [9].

\section{Definition of Hyperuricaemia}

Uric acid is the end product of purine metabolism in humans and increased serum urate levels may be seen due to high dietary purine intake (particularly shellfish, red meat and beer), in conditions of increased cell turnover or cell death (for example following cytotoxic chemotherapy) and if renal function is impaired (urate is approximately $70 \%$ renally excreted). Urate levels generally rise with increasing age and hyperuricaemia is also seen in the metabolic syndrome partly due to hyperinsulinemia impairing urate excretion [10]. The definition of hyperuricaemia varies but is generally considered to be levels above the serum saturation point of uric acid (approximately $6.8 \mathrm{mg} / \mathrm{dL}$ ). Above this level uric acid may precipitate out of solution and be deposited in joints and tissues causing the recognised complication of gout. Guidelines for the management of gout recommend achieving serum urate levels below $6 \mathrm{mg} / \mathrm{dL}$ in order to reduce gout flares and complications [11]. There are currently no guidelines or recommendations for the management of asymptomatic hyperuricaemia.

\section{Hyperuricaemia and Evolution}

Hyperuricaemia is an almost uniquely human problem due to the fact that humans have a loss of function mutation affecting the uricase enzyme which prevents further breakdown of uric acid into more soluble waste products. This mutation occurred over 15 million years ago, during a time of intense climatic upheaval when food, water and salt supplies were scarce, and resulted in significantly higher serum urate levels in humans than in most other mammals. This mutation is thought to have conferred an evolutionary advantage by enabling our early ancestors to retain sodium, maintain blood pressure with a salt poor diet and augment fat storage from fructose found in fruits 
$[12,13]$. Unfortunately, in the modern world with increasingly sedentary lifestyles and the plentiful availability of high salt, energy dense food this evolutionary adaptation for survival is now potentially one of the factors contributing to the current worldwide epidemic of hypertension, obesity and the metabolic syndrome [14].

\section{Historical Association of Hyperuricaemia and Hypertension}

Hyperuricaemia is currently viewed solely as an important risk factor in the development of gout but is not otherwise routinely measured or monitored. Historically, however, hyperuricaemia has been closely associated with elevated blood pressure, for example, a paper published in the Lancet in 1879 noted that many gout patients were hypertensive and a subsequent BMJ review of "arterial tension" in 1889 recommended a low purine diet for the management of hypertension [15,16]. Hyperuricaemia fell out of favour as a cardiovascular risk factor in the 1970's and 80's (and consequently measurement of serum urate was removed from many standard blood testing panels) partly due to the lack of evidence of a causal association and partly due to concerns regarding side effects of medication used to manage what was considered to be an asymptomatic condition.

The establishment of plausible biological mechanisms for the relationship between hyperuricaemia and hypertension has been facilitated by the development of animal models of hyperuricaemia. This information, coupled with large observational studies in human populations have provided a growing body of evidence pointing strongly to a causal relationship between hyperuricaemia and the development of hypertension [17].

\section{Biological Mechanisms for Hyperuricaemia Induced Hypertension}

The first animal models of hyperuricaemia were developed in the 1990 's and used oxonic acid as an uricase inhibitor. Initial work in rats showed that after 2 weeks exposure to mild increases in urate levels, there was activation of the renin angiotensisin system and decrease in plasma nitrates leading to vasoconstriction and hypertension [18]. This hypertension was reversible by either stopping the oxonic acid (allowing the uricase enzyme to function normally) or by lowering urate levels with either xanthine oxidase inhibitors or uricosuric agents. This early hypertension was also responsive to treatment with blockade of the renin-angiotensin system [19].

When hyperuricaemia was induced in normal and remnant kidney rats it resulted in renal cortical vasoconstriction, glomerular hypertension and inflammatory cell infiltration, and the vascular damage recorded was much more severe in the remnant kidney rats. It was surmised that in this model, hyperuricaemia impaired the autoregulatory responses of afferent arterioles resulting in glomerular hypertension and vascular wall thickening to produce renal hypoperfusion. This led to renal ischaemia and subsequent tubulointerstitial inflammation, fibrosis and arterial hypertension [20]. Importantly these effects were not seen in rats treated with allopurinol which prevented the rise in urate levels.

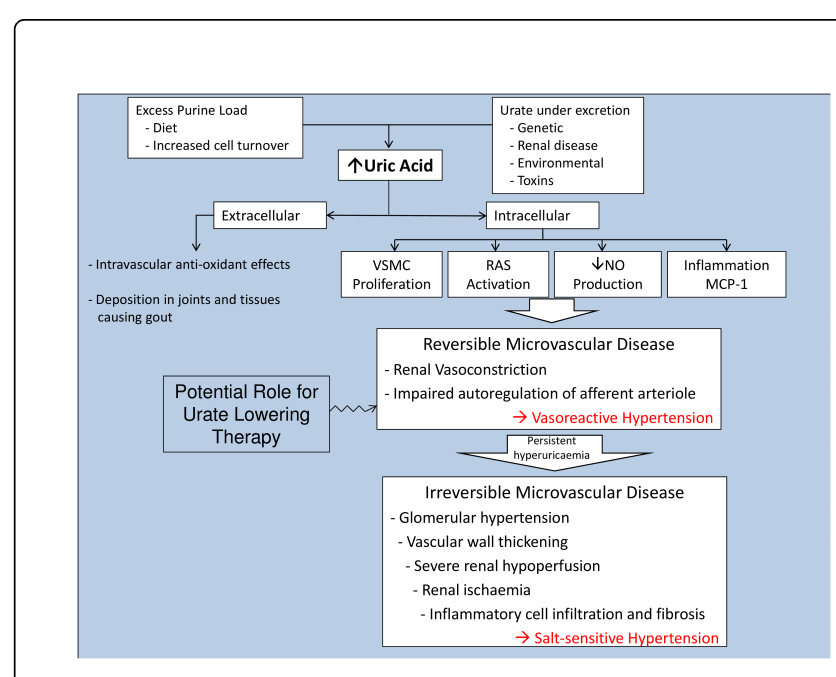

Figure 1: Hyperuricaemia induced hypertension

A two stage hypertension theory has emerged from this experimental work in rats. The initial vascular changes and subsequent hypertension seen in response to hyperuricaemia can be reversed, however, after prolonged exposure to high urate levels there is a second phase of hypertension with evidence of altered intra-renal architecture [21]. The pattern of renal microvascular damage is similar to that seen in patients with essential hypertension where, over time, there is evidence of tubular ischaemia, interstitial inflammatory cell infiltration, oxidant generation and local vasoconstriction resulting in reduction of sodium filtration, enhanced sodium reabsorption and hypertension that is mainly salt sensitive $[13,22]$. In both cases these vascular changes become irreversible over time which may explain the observation that the link between hyperuricaemia and hypertension appears stronger in younger people [23].

\section{Evidence from Epidemiological studies}

Since the revival of interest in the role of hyperuricaemia in the development of hypertension and as a potential independent cardiovascular risk factor, there has been an exponential rise in the number of papers published demonstrating and discussing this link [24]. Two recent meta-analyses looking specifically at hyperuricaemia and hypertension have concluded that higher urate levels predict the development of hypertension. Meta-analysis by Zhang and colleagues in 2009 included their prospective cohort study of 7220 normotensive Chinese patients with 4 years follow up. The adjusted relative risk of developing hypertension was 1.55 in men and 1.91 in women for the highest quartiles of serum urate compared with the lowest quartiles. When included with 7 other studies in the meta-analysis (total 28,657 participants) there was a pooled relative risk of 1.55 for development of hypertension in those with the highest quartiles of serum urate. In Zhang's original study the association between hyperuricaemia and hypertension appeared to be partly mediated by abdominal obesity and it was postulated that this was due to hyperinsulinaemia enhancing uric acid reabsorption [25]. In 2011 Grayson conducted a meta-analysis of 18 published, prospective cohort studies (including the 8 studies used by Zhang) comprising a total of 55,607 patients (Table 1) [25-42]. This meta-analysis showed that hyperuricaemia was associated with an increased risk for incident hypertension (adjusted 
Page 3 of 6

risk ratio 1.41) and for every $1 \mathrm{mg} / \mathrm{dL}$ increase in serum urate the pooled risk ratio for incident hypertension (after correcting for confounding factors) was 1.13. The risk appeared to be more significant in younger people and in women [23]. These two metaanalyses included studies from Europe, China, Japan, Israel and the USA indicating that this relationship is seen across ethnic groups.

\begin{tabular}{|c|c|c|}
\hline Author & Population & Risk \\
\hline Forman [29] & Nurses Health Survey (US), n=1496 & OR for incident hypertension $1.89 ; 95 \% \mathrm{Cl} 1.26-2.82$ \\
\hline Zhang [27] & $\begin{array}{l}\text { Qingdao Port Health and Nutrition } 7220 \text { Examination Survey in China, mean } \\
\text { age } 37\end{array}$ & $\begin{array}{l}\text { Adjusted RR for incident hypertension men } 1.55 ; 95 \% \mathrm{Cl} \\
1.10-2.19 \text { and women } 1.91 ; 95 \% \mathrm{Cl} 1.12-3.25)\end{array}$ \\
\hline Forman [30] & Health Professionals Follow up Study (US), n=1454 (men only) & Adjusted RR $1.24 ; 95 \% \mathrm{Cl} 0.93$ to 1.66 \\
\hline Krishnan [31] & Multiple Risk Factor Intervention Trial (US), n=3073 & Hazard ratio $1.81 ; 95 \% \mathrm{Cl}: 1.59$ to 2.07 for incident hypertension \\
\hline Mellen [32] & Atherosclerosis Risk in Communities (ARIC) study (US), n=9104 & $\begin{array}{l}\text { Adjusted hazard ratio for incident hypertension for each SD of } \\
\text { higher uric acid } 1.10 ; 95 \% \mathrm{Cl} 1.04 \text { to } 1.15\end{array}$ \\
\hline Perlstein [33] & Normative Aging Study (US), n=2062 & Age adjusted RR $1.10 ; 95 \% \mathrm{Cl}: 1.06$ to 1.15 \\
\hline Shankar [34] & Beaver Dam Population Cohort (US), $n=2520$ & RR for incident hypertension $1.65 ; 95 \% \mathrm{Cl} 1.41-1.93$ \\
\hline Sundstrom [28] & Framingham (US), $n=3329$ & $\begin{array}{l}\text { Adjusted OR for incident hypertension } 1.17 ; 95 \% \mathrm{Cl} 1.02-1.33 \text { for } \\
\text { every } 1 \text { SD increase in SUA }\end{array}$ \\
\hline Nagahama [35] & $\begin{array}{l}\text { Okinawa General Health Maintenance Association (OGHMA) cohort } \\
\text { (Japan), } n=4489\end{array}$ & $\begin{array}{l}\text { Adjusted OR for incident hypertension, men } 1.48 ; 95 \% \mathrm{Cl} \\
1.08-2.02 \text {, women } 1.90 ; 95 \% \mathrm{Cl} 1.03-3.51\end{array}$ \\
\hline Nakanishi [36] & Male office workers (Japan), $n=2310$ & Adjusted RR for incident hypertension $1.58 ; 95 \% \mathrm{Cl} 1.26-1.99$ \\
\hline Taniguchi [37] & Osaka Health Survey (Japan), n=6356 & Adjusted RR incident hypertension $2.01 ; 95 \%$ Cl 1.56-2.59 \\
\hline Imazu [38] & Hawai, Los Angeles Hiroshima Study (US/Japan), n=159 & Adjusted RR for incident hypertension $2.03 ; 95 \% \mathrm{Cl} 1.02-3.90$ \\
\hline Dyer [39] & $\begin{array}{l}\text { Coronary Artery Risk Development in Young Adults (CARDIA) study (US), } \\
n=4747\end{array}$ & $\begin{array}{l}\text { Multivariate OR for incident hypertension, black men } 1.21 ; 95 \% \mathrm{Cl} \\
1.03-1.41, \text { white men } 1.16 ; 95 \% \mathrm{Cl} 0.96-1.40\end{array}$ \\
\hline Jossa [40] & Olivettic Heart Study (Italy), n=505 & Adjusted RR for incident hypertension 1.23; 95\% Cl1.07-1.39 \\
\hline Hunt [41] & Utah Cardiovascular Genetics Study (US), n=1482 & Adjusted RR for incident hypertension $2.16(p<0.10)$ \\
\hline Selby [42] & Kaiser Permanente Multiphasic Health Checkup (US), n=2062 & RR for incident hypertension $2.19 ; 95 \% \mathrm{Cl} 1.2-3.98$ \\
\hline Fessel [43] & Target population and screening program (US), $n=335$ & Data not available \\
\hline Kahn [44] & The Israel Ischaemic Heart Disease Study, n=2904 & RR for incident hypertension $1.82 ; 95 \% \mathrm{Cl} 1.3-2.54$ \\
\hline
\end{tabular}

Table 1: Studies used in Grayson meta-analysis linking hyperuricaemia and hypertension, [Abbreviations: RR: Relative Risk, OR: Odds Ratio, HR: Hazard Ratio, CI: Confidence Interval, SUA: Serum Uric Acid Level]

Other studies not included in the above meta-analyses include the Bogalusa Heart study which looked at 577 US children, followed up for a mean of 11.4 years and showed that childhood urate levels significantly predicted hypertension in adult life [43]. The Taiwanese Health Survey from 2012 comprising 3257 patients showed that high serum urate was an independent predictor of blood pressure progression (HR 1.78) and incident hypertension (HR 1.68) [44]. A small Turkish study looking at 112 hypertensive patients with $24 \mathrm{hr}$ ABPM readings, categorised patients as dippers or non-dippers depending on blood pressure fall during the night. Loss of nocturnal blood pressure dipping is associated with worse cardiovascular outcomes and in this study the non-dippers had significantly higher urate levels than the dippers (OR 2.28) [45].

The epidemiological evidence to date does indicate a strong association between hyperuricaemia and hypertension and the diversity of ages and ethnic groups studied and the length of follow up lend weight to the argument that this association is causal, rather than representative of two conditions that share the same risk factors.
However, epidemiological evidence does not provide conclusive proof of causality and further experimental work and evidence from interventional trials are required to firmly establish the nature of this relationship.

\section{Management of Hyperuricaemia - Clinical Trial Data}

If hyperuricaemia is accepted as a potential causal factor for the development of essential hypertension then does reducing serum urate levels protect against the development of hypertension? A number of clinical trials over the past decade have sought to answer this question through either lowering urate levels with xanthine oxidase inhibitors or through use of uricosuric agents. The method by which urate lowering is achieved is important when looking at outcomes. Uricosuric agents such as probenecid act via the renal tubules and lower urate levels by increased renal excretion. Xanthine oxidase inhibitors (XOi) act by blocking the conversion of hypoxanthine to xanthine (the precursor of uric acid) and generally have a more potent 
effect on lowering urate levels than uricosuric agents. Allopurinol is the most commonly used XOi and is non-selective so not only reduces levels of uric acid but also inhibits other reactions in the purine/ pyrimidine metabolism pathways thereby preventing production of oxidants generated during this process [46]. It is hypothesised that allopurinol improves vascular outcomes due to this non-selectivity and by reducing oxidative stress rather than simply through reduction of urate levels. Febuxostat is a non-purine XOi and therefore more selective than allopurinol resulting in greater reductions in urate levels but with potentially less anti-oxidant effect [47]. It remains to be seen whether different cardiovascular effects will be found with febuxostat compared to allopurinol due to their selectivity of action.

Small pilot studies have been undertaken using allopurinol in hypertensive patients and particularly striking results have been seen in obese and newly diagnosed adolescents with hypertension. A randomised, placebo controlled trial in US adolescents with newly diagnosed essential hypertension showed that allopurinol 200mg twice daily resulted in a mean $24 \mathrm{hr}$ blood pressure change of $-6.3 \mathrm{mmHg}$ systolic and -4.6 diastolic compared to 0.8 systolic and -0.3 diastolic for the placebo group. These changes were significant although limited by the small sample size of only 30 adolescents [48]. A further study in 60 pre-hypertensive obese 11-17 year olds found that those treated with urate lowering therapy saw a reduction in clinic BP compared with the placebo group $(-10.3 /-8.0 \mathrm{mmHg}$ adjusted with allopurinol and $-10.2 /-8.8 \mathrm{mmHg}$ adjusted with probenecid). They concluded that uric acid contributed to the development of hypertension in adolescents and this effect could be mitigated by urate lowering therapy [49].

There have also been small trials in adults looking at the effect of allopurinol on patients with asymptomatic hyperuricaemia. 48 patients treated for 3 months with $300 \mathrm{mg}$ allopurinol daily showed decreased urate levels, decreased CRP, increase in eGFR and decreased blood pressure (-3.9/-1.9 $\mathrm{mmHg}$ ) compared with control groups [50]. Another trial compared 30 asymptomatic hyperuricaemic patients treated with allopurinol with 37 asymptomatic hyperuricaemic controls and 30 normouricaemic controls and showed that systolic blood pressure after 4 months decreased by $8 \mathrm{mmHg}$ in treated patients compared with controls [51]. Therefore asymptomatic patients with no prior history of hypertension responded to allopurinol treatment with a reduction in blood pressure.

A recent systematic review and meta-analysis of allopurinol use in reducing blood pressure looked at 10 studies, comprising a total of 738 participants. The authors found that, compared with the control group, treatment with allopurinol lowered systolic blood pressure by $3.3 \mathrm{mmHg}$ and diastolic blood pressure by $1.3 \mathrm{mmHg}$. They concluded that allopurinol had a small but significant effect in lowering blood pressure that could be exploited in managing hypertension in hyperuricaemic patients [52].

The majority of interventional studies to date have looked at using allopurinol to lower urate levels however there are alternative treatment options available. One drug that is particularly interesting in this field is losartan as it has a mildly uricosuric action which is unique in the angiotensin II receptor blocker (ARB) class. The Losartan Intervention For Endpoint reduction in hypertension (LIFE) study showed that a losartan based regimen was superior to an atenolol based regimen for reduction of cardiovascular mortality and morbidity despite comparable blood pressure reduction [53]. It was hypothesised that this could have been due to the uricosuric action of losartan and a further analysis concluded that over the 4.8 year follow up in LIFE the increase in serum urate seen over time was attenuated by losartan and this appeared to explain $29 \%$ of the treatment effect on the primary endpoint (cardiovascular death, MI or stroke) [54]. The association between serum urate and cardiovascular events was again noted to be stronger in women in this study.

The main concern with widespread use of allopurinol to manage hyperuricaemia in asymptomatic patients is the potential for side effects. Approximately $1 \%$ of patients prescribed allopurinol will develop a rash and in a very small proportion this can develop into the potentially life threatening allopurinol hypersensitivity reaction. Dose reductions of allopurinol are also recommended in renal impairment. An alternative XOi, febuxostat, has been licensed since 2008 and is more selective and more potent at lowering urate than $300 \mathrm{mg}$ of allopurinol [55]. Febuxostat shares some cross reactivity with allopurinol and similar rates of side effects have been reported however, febuxostat undergoes mainly biliary excretion and therefore does not require dose reductions in renal impairment $[55,56]$. The impact of febuxostat on blood pressure in humans has yet to be established and it will be interesting to see if more potent urate lowering has a more significant effect on blood pressure or whether the increased selectivity of febuxostat will make it less effective than allopurinol in this context.

\section{Hyperuricaemia and Cardiovascular Outcomes}

Following over a decade of intensive research in this area what has emerged is broad acceptance of a correlation between hyperuricaemia and hypertension and a clearer picture of a causal link, particularly for a subset of patients. There is however ongoing scepticism about the significance of hyperuricaemia induced hypertension in determining cardiovascular outcomes and more importantly whether modifying serum urate levels will influence these outcomes in a substantial way. The evidence looking at hyperuricaemia and cardiovascular outcomes shows mixed results. The European Working Party on High Blood Pressure in the elderly found no relationship between urate levels and cardiovascular outcomes however the patients studied were enrolled in a trial of diuretics which may have confounded the results [57]. Data from the Framingham Heart study which included 6763 Framingham participants with measurements of serum urate taken between 1971 and 1976 showed that after adjusting for other risk factors, urate levels did not predict adverse cardiovascular outcomes. The authors concluded that elevated serum urate does not have a causal role in the development of coronary heart disease, death from cardiovascular disease, or death from all causes [58]. A meta-analysis of 11 trials involving 21,373 participants looking at changes in serum urate and cardiovascular events found that there was no relationship between changes in urate levels and outcomes [59]. The authors acknowledged that hyperuricaemic patients are at increased risk of cardiovascular events however as many of the risk factors for hyperuricaemia are the same risk factors as for cardiovascular disease the difficulty remains in separating out the individual effect of hyperuricaemia [59-61]. This also confirms the ongoing doubt surrounding the best management of hyperuricaemia as evidence that aggressive treatment of hyperuricaemia improves overall cardiovascular outcomes is lacking.

\section{Conclusions}

Undoubtedly the effect of hyperuricaemia in the human body is complex. At present evidence is accumulating that hyperuricaemia could be a significant factor in the development of hypertension in some people, and importantly, hyperuricaemia is also a potentially 
reversible risk factor. Hypertension is a significant global health problem and a key contributor to increased risk of cardiovascular events, therefore any intervention that could improve the management of hypertension requires careful examination. There remains an unanswered question over whether aggressive management of hyperuricaemia can reduce blood pressure and improve cardiovascular outcomes significantly enough to be cost effective and outweigh the potential side effects of the urate lowering therapies required. Large randomised controlled trials are needed to answer this question, and it is possible that in the future management of hyperuricaemia will be as routine as management of cholesterol in the context of modifying cardiovascular risk.

\section{References}

1. Kearney PM, Whelton M, Reynolds K, Muntner P, Whelton PK, et al. (2005) Global burden of hypertension: analysis of worldwide data. Lancet 365: 217-223.

2. WHO (2009) Global Health Risks: Mortality and Burden of Disease Attributable to Selected Major Risks. Geneva.

3. Health and Social Care Information Centre (2010). Health Survey for England.

4. National Institute for Health and Clinical Excellence (NICE) (2011) CG127 Hypertension -Clinical management of primary hypertension in adults guidelines.

5. Billiet L, Doaty S, Katz JD, Velasquez MT (2014) Review of hyperuricemia as new marker for metabolic syndrome. ISRN Rheumatol 2014: 852954

6. Johnson RJ, Nakagawa T, Jalal D, Sánchez-Lozada LG, Kang DH, et al. (2013) Uric acid and chronic kidney disease: which is chasing which? Nephrol Dial Transplant 28: 2221-2228.

7. Gustafsson D, Unwin R (2013) The pathophysiology of hyperuricaemia and its possible relationship to cardiovascular disease, morbidity and mortality. BMC Nephrol 14: 164.

8. Gois PH, Souza ER (2013) Pharmacotherapy for hyperuricemia in hypertensive patients. Cochrane Database Syst Rev 1: CD008652.

9. Lucas PJ, Baird J, Arai L, Law C, Roberts HM (2007) Worked examples of alternative methods for the synthesis of qualitative and quantitative research in systematic reviews. BMC Med Res Methodol 7: 4.

10. Li C, Hsieh MC, Chang SJ (2013) Metabolic syndrome, diabetes, and hyperuricemia. Curr Opin Rheumatol 25: 210-216.

11. Khanna D, Fitzgerald JD, Khanna PP, Bae S, Singh MK, et al. (2012) 2012 American College of Rheumatology guidelines for management of gout Part 1: systematic nonpharmacologic and pharmacologic therapeutic approaches to hyperuricemia. Arthritis Care Res (Hoboken) 64: 1431-1446.

12. Johnson RJ, Sautin YY, Oliver WJ, Roncal C, Mu W, et al. (2009) Lessons from comparative physiology: could uric acid represent a physiologic alarm signal gone awry in western society? J Comp Physiol B.179:67-76.

13. Watanabe S, Kang DH, Feng L, Nakagawa T, Kanellis J, et al. (2002) Uric acid, hominoid evolution, and the pathogenesis of salt-sensitivity. Hypertension 40: 355-360.

14. Johnson RJ, Lanaspa MA, Gaucher EA (2011) Uric acid: a danger signal from the RNA world that may have a role in the epidemic of obesity, metabolic syndrome, and cardiorenal disease: evolutionary considerations. Semin Nephrol 31: 394-399.

15. Haig A (1889) On Uric Acid and Arterial Tension. Br Med J 1: 288-291.

16. Mahomed FA (1879) On chronic Bright's disease and its essential symptoms. Lancet 113: 399-401.

17. Jin M, Yang F, Yang I, Yin Y, Luo JJ, et al. (2012) Uric acid, hyperuricemia and vascular diseases. Front Biosci (Landmark Ed) 17: 656-669.
18. Mazzali M, Hughes J, Kim YG, Jefferson JA, Kang DH, et al. (2001) Elevated uric acid increases blood pressure in the rat by a novel crystalindependent mechanism. Hypertension 38: 1101-1106.

19. Mazzali M, Kanellis J, Han L, Feng L, Xia YY, et al. (2002) Hyperuricemia induces a primary renal arteriolopathy in rats by a blood pressureindependent mechanism. Am J Physiol Renal Physiol 282: F991-997.

20. Sánchez-Lozada LG, Tapia E, Santamaría J, Avila-Casado C, Soto V, et al. (2005) Mild hyperuricemia induces vasoconstriction and maintains glomerular hypertension in normal and remnant kidney rats. Kidney Int 67: 237-247.

21. Rodriguez-Iturbe B, Romero F, Johnson RJ (2007) Pathophysiological mechanisms of salt-dependent hypertension. Am J Kidney Dis 50: 655-672.

22. Kanellis J, Nakagawa T, Herrera-Acosta J, Schreiner GF, RodríguezIturbe B, et al. (2003) A single pathway for the development of essential hypertension. Cardiol Rev 11: 180-196.

23. Grayson PC, Kim SY, LaValley M, Choi HK (2011) Hyperuricemia and incident hypertension: a systematic review and meta-analysis. Arthritis Care Res (Hoboken) 63: 102-110.

24. Feig DI (2012) The role of uric acid in the pathogenesis of hypertension in the young. J Clin Hypertens (Greenwich) 14: 346-352.

25. Zhang W, Sun K, Yang Y, Zhang H, Hu FB, et al. (2009) Plasma uric acid and hypertension in a Chinese community: prospective study and metaanalysis. Clin Chem 55: 2026-2034.

26. Sundström J, Sullivan L, D'Agostino RB, Levy D, Kannel WB, et al. (2005) Relations of serum uric acid to longitudinal blood pressure tracking and hypertension incidence. Hypertension 45: 28-33.

27. Forman JP, Choi H, Curhan GC (2009) Uric acid and insulin sensitivity and risk of incident hypertension. Arch Intern Med 169: 155-162.

28. Forman JP, Choi H, Curhan GC (2007) Plasma uric acid level and risk for incident hypertension among men. J Am Soc Nephrol 18: 287-292.

29. Krishnan E, Kwoh CK, Schumacher HR, Kuller L (2007) Hyperuricemia and incidence of hypertension among men without metabolic syndrome. Hypertension 49: 298-303.

30. Mellen PB, Bleyer AJ, Erlinger TP, Evans GW, Nieto FJ, et al. (2006) Serum uric acid predicts incident hypertension in a biethnic cohort: the atherosclerosis risk in communities study. Hypertension 48: 1037-1042.

31. Perlstein TS, Gumieniak O, Williams GH, Sparrow D, Vokonas PS, et al. (2006) Uric acid and the development of hypertension: the normative aging study. Hypertension 48: 1031-1036.

32. Shankar A, Klein R, Klein BE, Nieto FJ (2006) The association between serum uric acid level and long-term incidence of hypertension: Population-based cohort study. J Hum Hypertens 20: 937-945.

33. Nagahama $\mathrm{K}$, Inoue $\mathrm{T}$, Iseki $\mathrm{K}$, Touma $\mathrm{T}$, Kinjo $\mathrm{K}$, et al. (2004) Hyperuricemia as a predictor of hypertension in a screened cohort in Okinawa, Japan. Hypertens Res 27: 835-841.

34. Nakanishi N, Okamoto M, Yoshida H, Matsuo Y, Suzuki K, et al. (2003) Serum uric acid and risk for development of hypertension and impaired fasting glucose or Type II diabetes in Japanese male office workers. Eur J Epidemiol 18: 523-530.

35. Taniguchi Y, Hayashi T, Tsumura K, Endo G, Fujii S, et al. (2001) Serum uric acid and the risk for hypertension and Type 2 diabetes in Japanese men: The Osaka Health Survey. J Hypertens 19: 1209-1215.

36. Imazu M, Yamamoto H, Toyofuku M, Sumii K, Okubo M, et al. (2001) Hyperinsulinemia for the development of hypertension: data from the Hawaii-Los Angeles-Hiroshima Study. Hypertens Res 24: 531-536.

37. Dyer AR, Liu K, Walsh M, Kiefe C, Jacobs DR Jr, et al. (1999) Ten-year incidence of elevated blood pressure and its predictors: the CARDIA study. Coronary Artery Risk Development in (Young) Adults. J Hum Hypertens 13: 13-21.

38. Jossa F, Farinaro E, Panico S, Krogh V, Celentano E, et al. (1994) Serum uric acid and hypertension: the Olivetti heart study. J Hum Hypertens 8: 677-681. 
Page 6 of 6

39. Hunt SC, Stephenson SH, Hopkins PN, Williams RR (1991) Predictors of an increased risk of future hypertension in Utah. A screening analysis. Hypertension 17: 969-976.

40. Selby JV, Friedman GD, Quesenberry CP Jr (1990) Precursors of essential hypertension: pulmonary function, heart rate, uric acid, serum cholesterol, and other serum chemistries. Am J Epidemiol 131: 1017-1027.

41. Fessel WJ, Siegelaub AB, Johnson ES (1973) Correlates and consequences of asymptomatic hyperuricemia. Arch Intern Med 132: 44-54.

42. Kahn HA, Medalie JH, Neufeld HN, Riss E, Goldbourt U (1972) The incidence of hypertension and associated factors: the Israel ischemic heart disease study. Am Heart J 84: 171-182.

43. Alper AB Jr, Chen W, Yau L, Srinivasan SR, Berenson GS, et al. (2005) Childhood uric acid predicts adult blood pressure: the Bogalusa Heart Study. Hypertension 45: 34-38.

44. Yang T, Chu CH, Bai CH, You SL, Chou YC, et al. (2012) Uric acid concentration as a risk marker for blood pressure progression and incident hypertension: a Chinese cohort study. Metabolism 61: 1747-1755.

45. Turak O, Ozcan F, Tok D, IÅŸleyen A, SÃkmen E, et al. (2013) Serum uric acid, inflammation, and nondipping circadian pattern in essential hypertension. J Clin Hypertens (Greenwich) 15: 7-13.

46. Johnson RJ, Sánchez-Lozada LG, Mazzali M, Feig DI, Kanbay M, et al. (2013) What are the key arguments against uric acid as a true risk factor for hypertension? Hypertension 61: 948-951.

47. Takano Y, Hase-Aoki K, Horiuchi H, Zhao L, Kasahara Y, et al. (2005) Selectivity of febuxostat, a novel non-purine inhibitor of xanthine oxidase/xanthine dehydrogenase. Life Sci 76: 1835-1847.

48. Feig DI, Soletsky B, Johnson RJ (2008) Effect of allopurinol on blood pressure of adolescents with newly diagnosed essential hypertension: a randomized trial. JAMA 300: 924-932.

49. Soletsky B, Feig DI (2012) Uric acid reduction rectifies prehypertension in obese adolescents. Hypertension 60: 1148-1156.

50. Kanbay M, Ozkara A, Selcoki Y, Isik B, Turgut F, et al. (2007) Effect of treatment of hyperuricemia with allopurinol on blood pressure, creatinine clearence, and proteinuria in patients with normal renal functions. Int Urol Nephrol 39: 1227-1233.

51. Kanbay M, Huddam B, Azak A, Solak Y, Kadioglu GK, et al. (2011) A Randomized Study of Allopurinol on Endothelial Function and
Estimated Glomular Filtration Rate in Asymptomatic Hyperuricemic Subjects with Normal Renal Function. Clin J Am Soc Nephrol 6: 1887-1894.

52. Agarwal V, Hans N, Messerli FH (2013) Effect of allopurinol on blood pressure: a systematic review and meta-analysis. J Clin Hypertens (Greenwich) 15: 435-442.

53. Dahlöf B, Devereux RB, Kjeldsen SE, Julius S, Beevers G, et al. (2002) Cardiovascular morbidity and mortality in the Losartan Intervention For Endpoint reduction in hypertension study (LIFE): a randomised trial against atenolol. Lancet 359: 995-1003.

54. Høieggen A, Alderman MH, Kjeldsen SE, Julius S, Devereux RB, et al. (2004) The impact of serum uric acid on cardiovascular outcomes in the LIFE study. Kidney Int 65: 1041-1049.

55. Schumacher HR Jr, Becker MA, Wortmann RL, Macdonald PA, Hunt B, et al. (2008) Effects of febuxostat versus allopurinol and placebo in reducing serum urate in subjects with hyperuricemia and gout: a 28week, phase III, randomized, double-blind, parallel-group trial. Arthritis Rheum 59: 1540-1548.

56. $\mathrm{Hu} \mathrm{M}$, Tomlinson B (2008) Febuxostat in the management of hyperuricemia and chronic gout: a review. Ther Clin Risk Manag 4: 1209-1220.

57. Staessen J (1991) The determinants and prognostic significance of serum uric acid in elderly patients of the European Working Party on High Blood Pressure in the Elderly trial. Am J Med 90: 50S-54S.

58. Culleton BF, Larson MG, Kannel WB, Levy D (1999) Serum uric acid and risk for cardiovascular disease and death: the Framingham Heart Study. Ann Intern Med 131: 7-13.

59. Savarese G, Ferri C, Trimarco B, Rosano G, Dellegrottaglie S, et al. (2013) Changes in serum uric acid levels and cardiovascular events: a metaanalysis. Nutr Metab Cardiovasc Dis 23: 707-714.

60. Navaneethan SD, Beddhu S (2009) Associations of serum uric acid with cardiovascular events and mortality in moderate chronic kidney disease. Nephrol Dial Transplant 24: 1260-1266.

61. Hanley A, Stack A (2011) The impact of gout and hyperuricaemia on total and cardiovascular mortality in the general population. European Heart Journal 32: 647-647. 